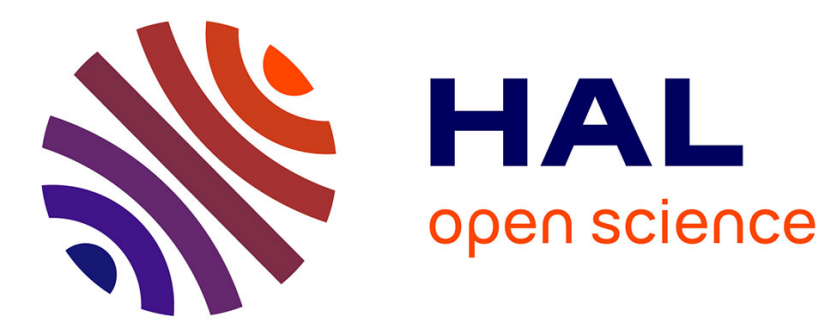

\title{
Molecular design of hybrid organic-inorganic materials
} Clément Sanchez, F. Ribot

\section{To cite this version:}

Clément Sanchez, F. Ribot. Molecular design of hybrid organic-inorganic materials. Journal de Physique IV Proceedings, 1993, 03 (C7), pp.C7-1349-C7-1355. 10.1051/jp4:19937207 . jpa-00251841

\section{HAL Id: jpa-00251841 https://hal.science/jpa-00251841}

Submitted on 1 Jan 1993

HAL is a multi-disciplinary open access archive for the deposit and dissemination of scientific research documents, whether they are published or not. The documents may come from teaching and research institutions in France or abroad, or from public or private research centers.
L'archive ouverte pluridisciplinaire HAL, est destinée au dépôt et à la diffusion de documents scientifiques de niveau recherche, publiés ou non, émanant des établissements d'enseignement et de recherche français ou étrangers, des laboratoires publics ou privés. 


\title{
Molecular design of hybrid organic-inorganic materials
}

\author{
C. SANCHEZ and F. RIBOT \\ Laboratoire de Chimie de la Matière Condensée, URA 1466, Tour 54, 5ème étage, 4 place Jussieu, \\ 75252 Paris cedex 05, France
}

\begin{abstract}
Hybrid organic-inorganic materials offer a wide range of interesting applications especially in optics. Chemistry plays a major role in the elaboration and comprehension of such materials. Sol-gel process provide a method to blend, down to the molecular scale, organic and inorganic components. Examples of hybrid organic-inorganic materials for optics and optical characterizations of hybrid materials are given here.
\end{abstract}

\section{I - INTRODUCTION}

The interest for sol-gel materials is not only related to their physical and chemical properties, but also to the wide possibilities of materials processing offer by the colloidal state. The viscosity of sols easily allows to prepare films by dip-coating, spraying or spin coating [1]. The chemistry involved in sol-gel process is based on inorganic polymerization [2,3]. In the organic route, precursors are usually metallo-organic compounds such as alkoxides : $M(O R)_{n}(M=S i, T i, Z r, A l, \ldots$, $\left.\mathrm{OR}=\mathrm{OC}_{n} \mathrm{H}_{2 \mathrm{n}+1}\right)$. The initiation step of the polymerization corresponds to hydrolysis reactions where water molecules form reactive $\mathrm{M}-\mathrm{OH}$ groups and alcohol molecules are released in the solution. The propagation step corresponds to polycondensation reactions which yield, by eliminating water or alcohol, oxo bridges (M-O-M) or hydroxo bridges (M-OH-M) from hydroxo and non hydrolysed alkoxo groups. An oxo-hydroxo polymeric network is thus formed.

The various characteristics of sol-gel process (metallo-organic precursors, organic solvents, low processing temperatures) allow to introduce "fragile" organic molecules inside an inorganic network. Such organic molecules can improve the characteristics of the matrices. One can mention as examples: modification of the mechanical properties [4], easier processing of films and fibers, near shape moulding of various pieces for integrated optics [5], porosity control and adjustment of the hydrophilic/hydrophobic balance [6]. Moreover, the organic compounds may contribute to a peculiar physical or chemical property (optical [7-10] or electrical [11] properties, electrochemical reactions [12], chemical or biochemical reactivity [13-17]). On the other hand, the inorganic part of the material contributes to its mechanical and thermal strength [4], allows to modulate the optical index [18] and may lead to interesting electrochemical, electrical or magnetic properties. 
This field of materials research mainly rises from chemists skills and demonstrates the major role played by chemistry in advanced materials. Sol-gel process has allowed to synthesise new hybrid organic-inorganic polymers which are composites on a molecular scale and exhibit novel properties.

This paper deals with hybrid materials for optics elaborated by sol-gel process. The examples presented here mainly concern luminescence, non linear optical properties and photochromism.

\section{2 - MATERIALS FOR OPTICS}

The most commonly used precursors for hybrid materials are organically modified silicon alkoxides, $\mathrm{SiR}_{\mathrm{X}}\left(\mathrm{OR}^{\prime}\right)_{4-\mathrm{x}}$. The main reason comes from the stability of the $\mathrm{Si}-\mathrm{C}$ bond, towards hydrolysis, which provides an easy way to introduce the organic part. In this area, we are involved in the synthesis of mixed siloxane-transition metal oxide materials $(\mathrm{M}=\mathrm{Ti}, \mathrm{Zr}, \mathrm{Al}, \ldots$ ). We are looking for properties such as easy film processing, transparency and adjustment of the hydrophobic/hydrophilic balance within the scope of matrices for optical applications [20]. Materials made from siloxane chains cross linked by transition metal oxo-polymers yield hydrophobic films whose thickness can be easily adjusted from 1 to $50 \mu \mathrm{n}$. Various organic molecules can be incorporated or grafted in such films. The following examples illustrates the work currently under investigation.

\section{Absorption and emission properties}

Laser dyes such as Rhodamines 6G, Sulphorhodamine and Coumarine 4 (UV-Visible region) or HITC (near infra-red region) have been incorporated in hybrid organic-inorganic films prepared by hydrolysing and co-condensing diethoxydimethylsilane (DEDMS) and transition metal alkoxides (Zr, Ti, Al). The stability of R6G and C 4 dyes is good for most of the matrices $[9,19]$. Moreover, even for high concentrations $(0.03 \mathrm{M})$ rhodamines have a much lower tendency to aggregate [10,20] (Fig.1). Emission spectra can be easily observed and Laser effect has been evidenced for some of these systems. R6G dyes exhibit, under irradiation, a better stability in such matrices than when included in organic polymers [9]. These results show that these materials are promising candidates for solid dye Lasers.

The inorganic part also allows to incorporate various rare-earth's $\left(\mathrm{Nd}^{3+}, \mathrm{Sm}^{3+}, \mathrm{Dy}^{3+}, \mathrm{Er}^{3+}\right.$, $\mathrm{Tm}^{3+}$ ) in these hybrid polysiloxane-transition metal oxo-polymers materials which can be easily processed into films [21]. All these doped materials exhibit luminescence. Even neodymium fluorescence, usually quenched by the $\mathrm{OH}$ groups which remain in non-heated sol-gel systems, is clearly observed in these hybrid matrices (Fig.2). This effect is probably related to the hydrophobic nature of the polydimethylsiloxane chains which facilitate the elimination of residual hydroxyl groups [21].

\section{Non linear optical properties}

Dipolar organic molecules with highly delocalized electrons (Fig.3) can be incorporated in these hybrid matrices to yield materials with non linear optical properties. 


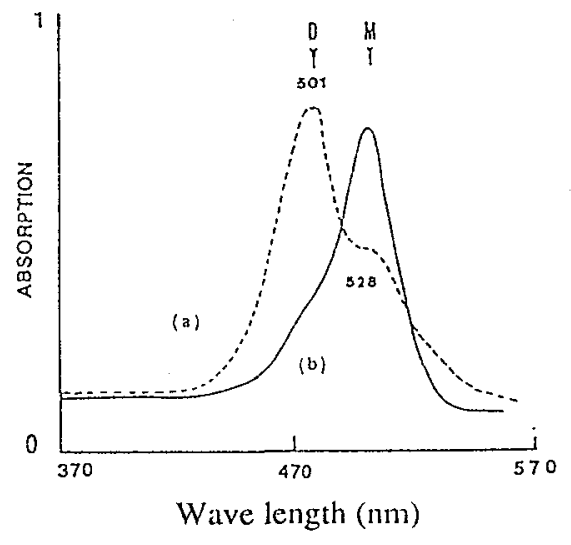

Fig. 1 : Absorption spectra of R6G in water (a) and in hybrid materials (b). ([R6G] $\left.=10^{-2} \mathrm{M}\right)$ $\mathrm{D}:$ Dimer and $\mathrm{M}$ : Monomer

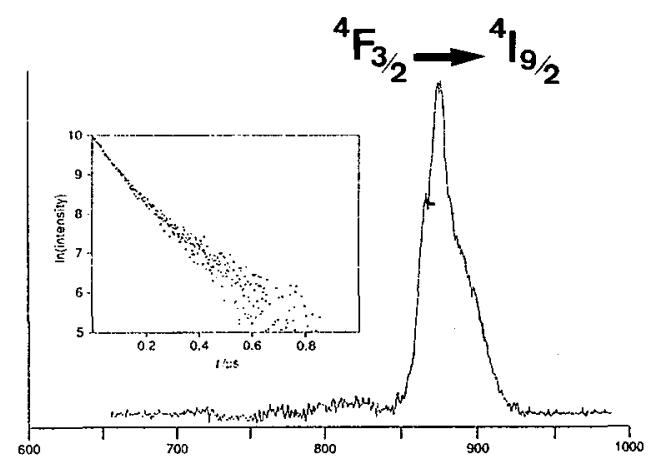

Wave length (nm)

Fig. $2: \mathrm{Nd}^{3+}$ emission spectrum and decay profile of $\mathrm{Nd}^{3+}$-doped hybrid coating.

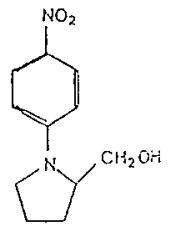

NPP

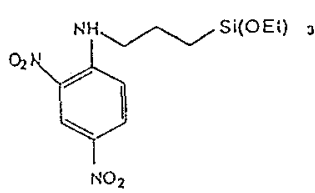

$\operatorname{Si}(N D)$

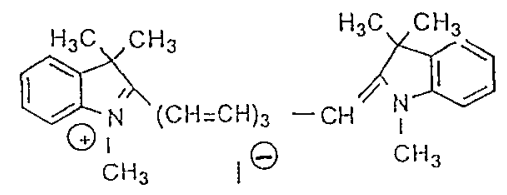

HITC

Fig. 3 : Organic molecules for non linear optics.

A dye, such as HITC, placed in various matrices exhibit cubic hyperpolarisability $(\gamma)$ of about $5000.10^{-36}$ esu. Its chemical stability can be improved by choosing proper compositions for the hybrid matrices [22,23]. The concentration of HITC can be as high as $0.1 \mathrm{M}$, which gives to the materials a non linear optical behaviour characterised by $\chi^{(3)} \approx 2.10^{-12}$ esu.

About quadratic susceptibility, we had to prove first, that in sol-gel systems a second order non linear effect was possible without any artefacts caused by the micro-crystallization of active molecules. Secondly, that these molecules could be oriented by applying an electric field in order to break down the centrosymmetry, caused by a random orientation of the chromophores, which cancel any second order properties [24]. Hybrid organic-inorganic films containing various chromophores such as the $\mathrm{N}$ (4-nitrophenyl)-L-prolinol (NPP) or the N-(3-triethoxysilyl-propyl)-2,4 dinitrophenyl amine (SiNФ) were prepared. After applying an electric field of $14 \mathrm{kV} / \mathrm{cm}$, non linear second order susceptibilities of about 1 to $10 \mathrm{pm} / \mathrm{V}$ were measured $[25,26]$.

The value obtained depends on the composition of the hybrid matrices, especially on the ratio siloxane/metal-oxo cross-linking species. The higher second order susceptibility was obtained when the molecule exhibiting non linear effect was grafted to the polymeric oxide network. This result 
comes from two main effects. First the solubility of the chromophore is increased when it is chemically bonded to the gel backbone. Secondly, the grafting allows to decrease the relaxation processes which lead to a loss in the order induced by the electric field and therefore in the non linear optical effect.

\section{Photochromic properties}

When tungsten oxo polymers are uses to cross linked polysiloxanes, photochromics hybrid films are obtained [27]. This effect arises from the intervalence transfer between to metal ions in two different oxidation states $\left(\mathrm{W}^{5+}-\mathrm{W}^{6+}\right)$. This transfer was evidenced by UV-visible absorption spectroscopy and electronic paramagnetic resonance. The reversibility of the photochromic process is quite fast $(\approx 1$ hour) for a system based on tungstate species.

Faster systems can be obtained when photochromism is due to a variation in the optical spectrum associated to a structural modification of an organic molecule. Such case is encountered with spirobenzopyrane incorporated or grafted in an hybrid matrix [28].

\section{Entirely novel hybrid materials}

All the materials previously mentioned, know as ORMOSILS (Organically Modified Silicates), have been highly developed in the past years, mainly because chemists have been using the skill they acquired in siloxanes research. The grafting of organic groups on oxide polymeric backbones is easily performed due to the stability of the $\mathrm{Si}-\mathrm{C}$ bond towards hydrolysis.

For transition metals, the $\mathrm{M}-\mathrm{C}$ bond is much more ionic and is therefore preferentially broken during hydrolysis. One way of circumventing this problem is to graft organic groups on the transition metal by using strongly complexing functions [29].

This strategy is currently adopted to elaborate hybrid organic-inorganic polymers whose inorganic part is only based on a transition metal ( $\mathrm{Ti}, \mathrm{Zr}$ ) [30,31]. These systems are synthesised from transition metal alkoxides partially complexed by AAEM (acetoacetoxyethylmethacrylate). Hydrolysis and radical polymerization are performed at the same time, yielding small oxo-polymeric species bound to one another by polymethacrylate chains whose size depends on the complexation ratio (AAEM/Zr) (Fig.4). For high complexation ratio ( $\approx 0.75)$, organic and inorganic networks are so tightly interpenetrated that materials are homogeneous down to the nanometer scale. The inorganic polymerization is also controlled by the complexation ratio and therefore the size of the transition metal oxo-polymers can be varied from nanometer to sub micrometer scale [30].

The organic part covalently bound to the inorganic part can be a polymer such as polymethymethacrylate (PMMA) or a molecule which has optical properties (methylnitroaniline : MNA, "Disperse red1", etc.). These transition metal based materials are more delicate to synthesise but they open up a wide range of coupled properties. One can think, for instance, of an hybrid material where the inorganic part exhibits electronic conduction or magnetic behaviour, simultaneously with a grafted optically active organic component.

These multifunctionnal hybrid materials allow to think to numerous applications in various fields: linear optics (solid dye laser, chemical or biochemical sensors), non linear optics 
(secondharmonic generation, filters, polarisers, logical devices) and environment (sensors, filters or membranes). Other applications involve "smart" materials which are able to adapt the effect to the cause. Photochromic materials are nice examples of such materials.
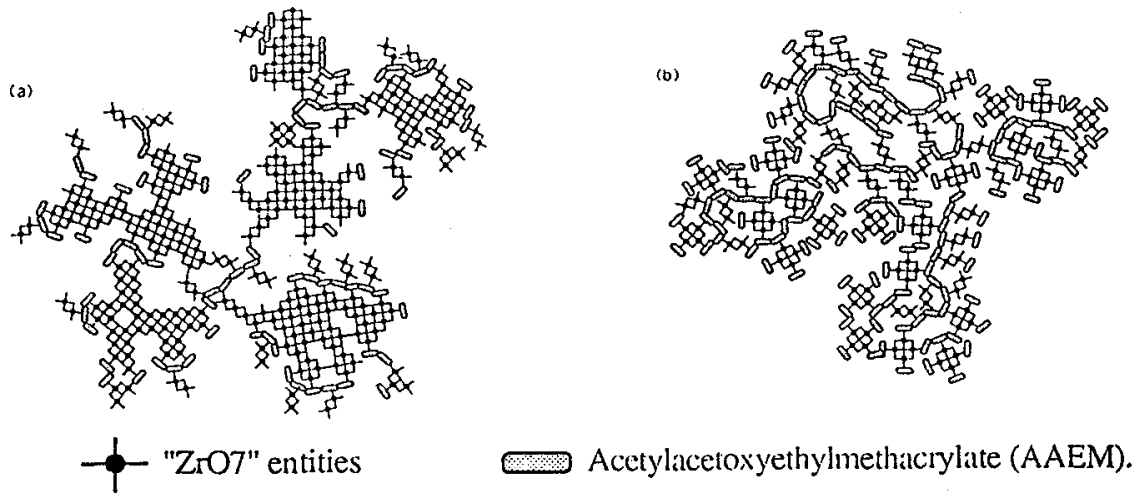

Fig. 4 : Cartoon of hybrid organic-inorganic networks for low (a) and high (b) complexation ratio.
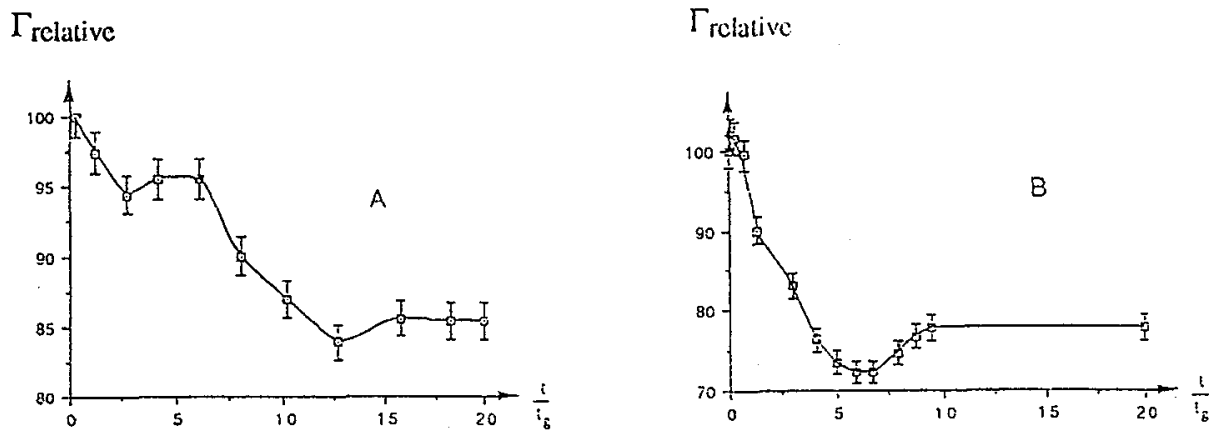

Fig.5 : EFISF signal for MNA doped $\mathrm{ZrO}_{2}$ based gel (a) and ASA grafted $\mathrm{ZrO}_{2}$ based gel (b)

\section{3 - OPTICS FOR MATERIALS}

Dynamic inside gels, probed by means of organic molecules, is an expending fundamental study. The physical properties associated to organic probes, embedded in gels, allow to investigate the growth and the aggregation of the polymeric species coming from the hydrolysis-condensation of alkoxides precursors. The changes, occurring on a microscopic scale in sol-gel systems, have been monitored by EFISH (Electrical Field Induced Second Harmonic) [24], luminescence [9] and chronoamperometry [32]. This research actually deals with questions similar to the ones involved in the measurement and the comprehension of molecular dynamic in restricted geometry.

The EFISH technique consists in applying, for a very short period of time $(\approx 1 \mu \mathrm{s})$, an electrical field to orient dipolar molecules and break down the centrosymmetry of random media such as solutions or gels. Simultaneously, the system is irradiated with a powerful Laser and the generated 
second harmonic is detected. This technique allows to measure the macroscopic quadratic susceptibility $(\Gamma)$ of a materials.

For the first time, it was used to follow the changes occurring in a sol-gel system during gelation. The relative macroscopic quadratic susceptibility $\left(\Gamma / \Gamma_{\mathrm{t}=0}\right)$ versus reduced time $(\mathrm{t} / \mathrm{get})$ is plot in figure 5 for two $\mathrm{ZrO}_{2}$ based sol-gel systems. The first one corresponds to MNA simply dissolved in the starting solution while for the second one the organic molecule, aminosalicylic acid (ASA), is chemically grafted on the polymeric network. First of all, one can see that the EFISH is sensitive to gels evolution. The gelation ( $t / \mathrm{tgel}_{\mathrm{ge}}=1$ ) is more strongly noticeable in the ASA system since the probe is grafted on the oxo-polymers. Then the ageing of the gel leads to a decrease of $\Gamma_{\text {relative. This }}$ phenomenon takes place between 5 and $15 \mathrm{t} / \mathrm{tgel}$. Yet, the reorientation mobility of the probe is still large as long as the gel is not dried.

These results show that, even though the gel is rigid on a macroscopic scale, the microscopic probes can still move as in a liquid. During the ageing step ( $5-15 \mathrm{t} / \mathrm{tgel}_{\mathrm{gel}}$, more and more oxo-polymers cross link and therefore the probes start to feel a restriction of its free volume. These observations agree with the gelation model proposed par Cabane et al. for systems obtained by hydrolysiscondensation of alkoxides [33]. In this model, a small amount of large polymers give rives to the macroscopic gelation while small polymers, which are more numerous, control the local density fluctuations. During ageing, these small species condense in the pores previously created by the larger polymers and restraint the mobility of embedded or grafted organic molecules.

\section{REFERENCES}

[1] "Sol-gel technology for thin films, fiber, preforms, electronics and especialty shapes", L.C. Klein (Eds.), (Noyes Pub,.1988).

[2] C.J. Brinker and G. Scherrer, "Sol-Gel Science, the Physics and Chemistry of Sol-gel Processing" (Academic press, San-Diego, 1989).

[3] (a) J. Livage, M. Henry and C. Sanchez, Progress in Solid State Chemistry 18, 259 (1988).

(b) C.Sanchez, F. Ribot, and S. Doeuff, in "Inorganic and Organometallic Polymers with Special Properties", R.M. Laine (Eds.) (Kluwer Academic Publishing, 1992) p.267.

[4] A. Morikawa, Y. Iyoku, M. Kakimoto and Y. Imai, J. Mater. Chem. 2(7), 679 (1992).

[5] H. Schmidt and M. Popall, in "Sol-Gel Optics", J.D. Mackenzie and D.R. Ulrich (Eds.), Proc. SPIE 1328, Washington (1990), p.249.

[6] K. Izumi, H. Tanaka, M. Murakami, T. Degushi, A. Morita, N. Toghe and T. Minami, J. NonCryst. Solids 121, 344 (1990).

[7] D. Avnir, D. Levy and R. Reisfeld, J. Phys. Chem. 88, 5956 (1984).

[8] "Sol-Gel Optics", J.D. Mackenzie and D.R. Ulrich (Eds.), Proc. SPIE 1328, Washington (1990).

[9] B. Dunn and J.I. Zink, J. Mater. Chem. 1(6), 903 (1991)

[10] C.Sanchez, in "Sol-Gel Optics", J.D. Mackenzie and D.R. Ulrich (Eds.), Proc. SPIE 1328, Washington (1990) p.40. 
[11] S.J. Kramer, M.W. Colby, J.D. Mackenzie, B.R. Mattes, and R.B. Kaner, in "Chemical Processing of Advanced Materials", L.L. Hench and J.K. West (Eds.) J. Wiley and Sons, NewYork (1992) p 737.

[12] P. Audebert, P. Griesmar and C. Sanchez, J .Mater. Chem. 1(4), 699 (1991).

[13] S. Braun, S. Rappoport, R. Zusman, D. Avnir and M. Ottolenghi, Mater. Lett. 10, 1(1990).

[14] L.M. Ellerby, C.R. Nishida, F. Nishida, S.A. Yamanaka, B. Dunn, J.S. Valentine and J.I. Zink, Science 255, 1113 (1992)

[15] S.A. Yamanaka, F. Nishida, L.M. Ellerby, C.R. Nishida, B. Dunn, J.S. Valentine and J.I. Zink, Chem. Mater. 4(3), 495 (1992).

[16] P. Audebert, C. Demaille and C. Sanchez, Mater. Chem. (1993) in press.

[17] D. Avenir, S. Braun, O. Lev and M. Ottolenghi, in "Sol-Gel Optics II", J.D. Mackenzie (Eds.), Proc. SPIE 1758, Washington (1992) p.456.

[18] H. Schmidt and B. Seiferling, Mat. Res. Soc. Symp. Proc. 73, 739.(1986).

[19] H.T. Lin, E. Bescher, J.D. Mackenzie, H. Dai and O.M. Stafsudd, J. Mater. Sci. 29, 442 (1992).

[20] S. Dire, F. Babonneau, C. Sanchez and J. Livage, Chem. Mater. 2 (2), 239 (1992)

[21] N. Koslova, B. Viana and C. Sanchez, J. Mater.Chem. 1(3), 111(1993).

[22] C. Sanchez, P. Griesmar, E. Toussaere, G. Puccetti, I. Ledoux and J. Zyss., Non Linear Optics 2 (1992).

[23] B. Lebeau, N. Herlet, J. Livage and C. Sanchez, Chem. Phys. letters 206, 15 (1993).

[24] P. Griesmar, C. Sanchez, G. Pucetti, I. Ledoux and J. Zyss, Molecular Engineering 1(3), 205 (1991).

[25] E. Toussaere, J. Zyss, P. Griesmar and C. Sanchez, Non Linear Optics 1, 349 (1991)

[26] B. Lebeau, C. Sanchez, E. Toussaere, R. Hierle and J. Zyss, in preparation.

[27] B. Lebeau and C. Sanchez, in preparation.

[28] (a) D.Levy and D. Avnir, J.Phys.Chem. 92, 4737 (1988).

(b) D. Levy, S. Einhom and D. Avnir, J. Non-Cryst. Solids 113, 137 (1989)

[29] C. Sanchez, J. Livage, M. Henry and F. Babonneau, J. Non-Cryst. Solids 100, 650 (1988).

[30] C. Sanchez and M. In, J. Non-Cryst. Solids 147-148, 1(1992)

[31] French patents. $n^{\circ}$ INPI 91 11634, 9111635 (M. In, C. Sanchez, J.C. Daniel)

[32] P. Audebert, P. Hapiot, P. Griesmar and C. Sanchez, J Mater. Chem. 1(4), 699 (1991).

[33] B. Cabane, M. Dubois and R. Duplessix, J.physique Paris 48, 2131(1987). 